\title{
A pilot study on the use of interferon beta-1a in early Alzheimer's disease subjects
}

\author{
Luigi Maria Edoardo Grimaldi ${ }^{*}$, Giuseppe Zappalà ${ }^{2}$, Francesco lemolo ${ }^{3}$, Anna Elisa Castellano ${ }^{4}$, Stefano Ruggieri ${ }^{3}$, \\ Giuseppe Bruno ${ }^{5}$ and Andrea Paolillo ${ }^{6}$
}

\begin{abstract}
Despite the fact that multiple sclerosis (MS) and Alzheimer's disease (AD) share common neuroimmunological features, interferon beta 1a (IFN 1 1a), the well-established treatment for the prevention of disease progression and cognitive decline in MS patients, has never been used in AD. We evaluated the safety and efficacy of IFNB1a in subjects affected by mild-to-moderate $A D$ in a double-blind, randomized, placebo-controlled, multicenter pilot study. Forty-two early Alzheimer's patients were randomized to receive either a 22 mcg subcutaneous injection of IFN 1 1 a or placebo three times per week. A treatment period of 28 weeks was followed by 24 weeks of observation. IFNß1a was well tolerated and adverse events were infrequent and mild to moderate. Although not statistically significant, a reduction in disease progression during follow-up was measured in IFN $\beta 1$ a-treated patients by the Alzheimer's Disease Assessment Scale cognitive subscale. Interestingly, the treatment group showed significant improvements in the Instrumental Activities of Daily Living and Physical Self-maintenance Scale. This study suggests that IFNB1a is safe and well tolerated in early AD patients, and its possible beneficial role should be further investigated in larger studies.
\end{abstract}

Keywords: Alzheimer's disease, clinical trials, randomized, controlled, multiple sclerosis, interferon

\section{Introduction}

Alzheimer disease (AD) is one of the major health problems affecting the aging world $[1,2]$. The disease is characterized by the accumulation in the brain of abnormally folded protein fragments (amyloid beta peptide, $A \beta$, and tau protein) forming amyloid plaques and neuronal tangles [3] whose appearance is associated with low-grade inflammation, advancing neuronal loss, and progressive cognitive decline. Plaque-associated microglia are able to respond to various stimuli by increasing their expression of histocompatibility complex (MHC) class II antigens and complement receptors as well as proinflammatory cytokines such as IL1 $\beta$, IL6, and tumor necrosis factoralpha (TNF- $\alpha$ ) [4-6]. In addition, vascular lesions affecting the cerebral endothelium can alter the blood-brain barrier (BBB), especially in $\mathrm{AD}$ patients with predisposing vascular abnormalities such as hypertension, cardiovascular disease and diabetes [7]. Similarly, in multiple sclerosis (MS),

\footnotetext{
* Correspondence: luigi.grimaldi@hsr.it

"U.O. di Neurologia, Fondazione Istituto San Raffaele "G. Giglio" di Cefalù, Contrada Pietrapollastra, 90015 Cefalù, PA, Italy

Full list of author information is available at the end of the article
}

an immune-mediated disease of the brain characterized by inflammatory-mediated degenerative processes affecting the white matter of the central nervous system and causing demyelination of neuronal axons, microglia and astrocytes are activated and express elevated MHC class II antigen expression, as well as intercellular adhesion molecules (ICAM-1) and proinflammatory cytokines including IL1 $\beta$, IL6 and TNF- $\alpha$ [8-11].

Interferon beta (IFN $\beta$ ) was first tested for its antiviral property for the possible involvement of viral infections in the pathogenesis of MS and is now widely used for its immunomodulatory and antiproliferative properties in the treatment of this demyelinating disease [12]. Some of the mechanism of action of IFN $\beta$ include a shift from pro- to anti-inflammatory cytokines production [13,14]; inhibition of T-cell activation, blockage of production of oxygen free radicals by mononuclear phagocytes, and reduced expression of MHC II [15]; a protective role against BBB disruption by reducing the activity of metalloproteases and thereby preventing T-cells infiltration in the CNS [16]; a neuroprotective effect on retinal ganglion cells 
survival and stimulation of the secretion of nerve growth factors by endothelial cells $[17,18]$.

Interestingly, IFN $\beta 1$ a significantly prevented cognitive decline in a large cohort of patients with MS, thus suggesting that modulation of neuroinflammatory pathways might prevent cognitive decline in humans [19].

At present, no effective treatment is available to stop disease progression in AD. Several immunomodulating strategies in experimental animal models and human clinical trials have recently attempted to alter the immunological pathways underlying the pathological changes seen in AD patients with conflicting results [20,21]. Based on the similarity of some of the immunopathological pathways shared by $\mathrm{AD}$ and MS, the similar alteration of the $\mathrm{BBB}$, as well as the positive effects on cognition in MS patients treated with IFN $\beta 1 \mathrm{a}$, we evaluated in a proof-ofconcept pilot trial the safety and possible efficacy of subcutaneous (s.c.) low dose IFN $\beta 1$ a in patients diagnosed with early mild $\mathrm{AD}$.

\section{Methods}

\section{Study design}

This double-blinded, randomized, placebo-controlled, multicenter pilot study (clinicaltrials.gov Identifier: NCT010 75763) was conducted according to the declaration of Helsinki. After receiving protocol approval from the Local Ethical Committee, we obtained informed consent from all patients. Patients were considered eligible if they were between 50 and 75 years of age, were diagnosed with $\mathrm{AD}$ according to the Diagnostic and Statistical Manual of Mental Disorders, 4th edition (DSM-IV), had a Mini Mental State Examination (MMSE) score between 20 and 26, and were supervised by a caregiver. Exclusion criteria included: use, in the previous 3 months, of statins, nonsteroidal anti-inflammatory drugs, steroids, or cholinesterase inhibitors that could modify the course of the disease; a Modified Hachinski Ischemic Score $\leq 4$; inability to undergo neuropsychological evaluation; significant liver, thyroid or hematological dysfunctions; severe cardiac disease, or epilepsy; a history of depression unresponsive to medication; past medical history of suicidal ideation; current use of hypnotic, anxiolytic, antidepressant, antipsychotic or anticholinergic drugs; and, finally, any known allergic reactions to interferons or other components of the study drug.

A total of 47 patients were screened at $5 \mathrm{AD}$ centers, and 42 patients were enrolled between December 2004 and May 2007. Patients' baseline characteristics are detailed in Tables 1 and 2.

Subjects were randomized into two groups: one $(n=23)$ receiving IFN $\beta 1$ a (Rebif ${ }^{\circ}$ Merck Serono S.A. - Geneva, Switzerland), 22 mcg subcutaneous injection (s.c.), three times per week; the other $(n=19)$ receiving placebo with the same schedule and route of administration. The
Table 1 Adverse events recorded in Placebo-and IFN $\beta$ 1-treated subjects

\begin{tabular}{|c|c|c|c|c|c|}
\hline \multirow{2}{*}{$\begin{array}{l}\text { Adverse event } \\
\text { Severity }\end{array}$} & \multicolumn{2}{|c|}{ Placebo } & \multicolumn{2}{|c|}{ IFN $\beta$ 1a } & \multirow[t]{2}{*}{ Total } \\
\hline & Mild & Moderate & Mild & Moderate & \\
\hline Articular pain & $2^{a}$ & 0 & 0 & 0 & 2 \\
\hline Fever & 0 & 0 & $1^{\mathrm{a}}$ & 0 & 1 \\
\hline High cholesterol & 0 & 0 & $3^{c}$ & 0 & 3 \\
\hline High level of ALT and AST & 0 & $1^{\mathrm{b}}$ & 0 & $1^{\mathrm{b}}$ & 2 \\
\hline High pseudocholinesterase & $1^{c}$ & 0 & $1^{c}$ & $1^{c}$ & 3 \\
\hline High triglycerides & 0 & 0 & 0 & $1^{c}$ & 1 \\
\hline High TSH & 0 & $1^{c}$ & 0 & 0 & 1 \\
\hline Low blood pressure & $1^{c}$ & 0 & 0 & 0 & 1 \\
\hline $\begin{array}{l}\text { Repolarization ventricular } \\
\text { anomaly }\end{array}$ & 0 & 0 & $1^{c}$ & 0 & 1 \\
\hline Right ear buzzing & $1^{\mathrm{b}}$ & 0 & 0 & 0 & 1 \\
\hline Flu-like syndrome & $1^{c}$ & 0 & 0 & 0 & 1 \\
\hline TOTAL & 6 & 2 & 6 & 3 & 17 \\
\hline
\end{tabular}

The number of adverse events in the two treatment arms is reported in details subdivided by severity degree. The relation to drug administration is shown as follows: ${ }^{a}$ probably related; ${ }^{b}$ unlikely related; ${ }^{c}$ unrelated. ALT, alanine aminotransferase; AST, aspartate aminotransferase; TSH, thyroid stimulating hormone.

treatment period was 28 weeks and patients were followed for up to 52 weeks (Figure 1). Outcome measures were monitored at baseline, week 28 , and week 52 . The primary efficacy evaluation was the Alzheimer's Disease Assessment Scale cognitive subscale (ADAS-Cog). Secondary efficacy evaluations included Global Deterioration Scale (Global DS), Clinician Interview Based Impression of Change (CIBIC-plus), Mini-Mental State Examination (MMSE), ADAS non-cognitive subscale (ADAS-NonCog), Instrumental Activities of Daily Living (IADL),

Table 2 Demographics and physical characteristics at baseline

\begin{tabular}{|c|c|c|c|}
\hline Characteristic & Placebo $^{a}$ & Interferon beta $1 a^{a}$ & $P$ value \\
\hline $\begin{array}{l}\text { Age at informed } \\
\text { consent (yrs) }\end{array}$ & $64.57 \pm 6.4$ & $63.0 \pm 9.07$ & 0.57 \\
\hline Height (cm) & $165.11 \pm 7.52$ & $163.0 \pm 9.01$ & 0.42 \\
\hline Weight (kg) & $71.59 \pm 9.92$ & $68.17 \pm 10.04$ & 0.27 \\
\hline $\begin{array}{l}\text { Systolic pressure } \\
(\mathrm{mmHg})\end{array}$ & $131.05 \pm 7.56$ & $164.74 \pm 18.26$ & 0.31 \\
\hline $\begin{array}{l}\text { Diastolic pressure } \\
(\mathrm{mmHg})\end{array}$ & $79.47 \pm 6.64$ & $116.26 \pm 19.2$ & 0.26 \\
\hline Pulse rate (bpm) & $70.94 \pm 11.88$ & $71.56 \pm 6.97$ & 0.86 \\
\hline Sex ${ }^{b}$ & $\begin{array}{l}8 \text { (male); } 11 \\
\text { (female) }\end{array}$ & $\begin{array}{l}8 \text { (male); } 15 \\
\text { (female) }\end{array}$ & 0.62 \\
\hline $\begin{array}{l}\text { Concomitant age- } \\
\text { related diseases } \\
\text { different from AD }\end{array}$ & 14 (yes); 4 (no) & 14 (yes); 8 (no) & 0.94 \\
\hline
\end{tabular}

${ }^{\mathrm{a}}$ Values are expressed as means $\pm \mathrm{SD} .{ }^{\mathrm{b}}$ Sex values are reported as absolute values. 


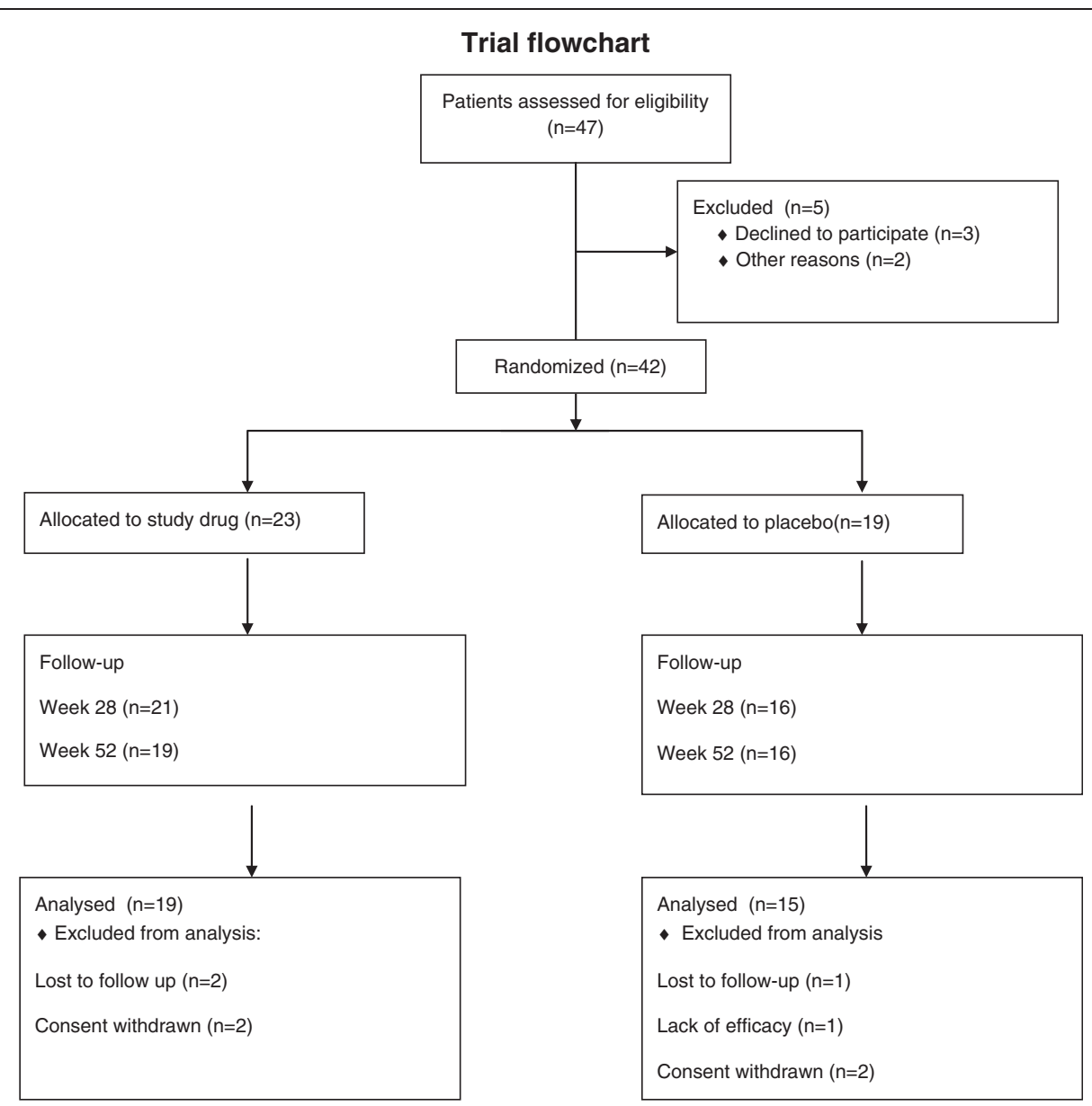

Figure 1 Trial flowchart giving details on the number of patients screened and taking part in each phase of the trial.

Physical Self-Maintenance Scale (PSMS), and Geriatric Depression Scale (GDS). At each routine visit serum chemistry, hematological, and urine abnormalities were evaluated, and physical and neurological examinations were performed.

\section{Statistical analysis}

Primary and secondary endpoints were assessed by armdescriptive analysis (mean, median, SD, range) of measured values at each time point and related changes over time. In addition, a preliminary assessment of normality was performed for each continuous scale. Mean differences with screening/baseline was tested using repeated measures T-test and ANOVA, as appropriate. The other secondary outcome measures were assessed at screening/ baseline and at week 12, week 28 and week 52 (Mini Mental Status Examination (MMSE), ADAS, non-cognitive subscale (ADAS-NonCog) or at week 28 and 52 (Instrumental Activities of Daily Living (IADL), Physical SelfMaintenance Scale (PSMS), Clinician's Interview Based Impression of Change (CIBIC-PLUS), Geriatric depression scale (GDS), and Global Deterioration Scale). Mean differences between follow-up and baseline of nonparametrically distributed variables (all test with the exception of GDS) were assessed using Wilcoxon scores and the Kruskal-Wallis test, while arm-specific differences were analyzed by Wilcoxon signed-rank test. Qualitative variables (for example, CIBIC-PLUS) were compared as proportions and tested using chi-square or Fischer exact tests, as appropriate.

\section{Results}

\section{Safety}

The study drug was well tolerated and adverse events were reported in $4 / 42$ (9\%) of the subjects, with no significant differences in the two arms. None of the adverse events were serious or resulted in death or early termination of study. The total number of adverse events was 17, 12 of which were mild and 5 were moderate. Moreover, only three of the adverse events were related to drug administration (Table 1). Ten events had resolved by the end of the study.

No significant changes in vital signs, or hematological or urinalysis parameters were reported; although, a mild 
Table 3 Neuropsychological tests values at baseline

\begin{tabular}{llll}
\hline Test & Placebo $^{\mathbf{a}}$ & Interferon beta $^{\mathbf{a}} \mathbf{a}^{\mathbf{a}}$ & $\boldsymbol{P}$ value \\
\hline ADAS-Cog $^{\mathrm{b}}$ & $19.81 \pm 6.14$ & $18.34 \pm 7.85$ & 0.34 \\
MMSE $^{\mathrm{c}}$ & $22.93 \pm 1.78$ & $23.45 \pm 2.13$ & 0.41 \\
ADAS-NonCog $^{\mathrm{d}}$ & $6.06 \pm 5.0$ & $4.36 \pm 4.12$ & 0.30 \\
PSMS $^{\mathrm{e}}$ & $6.4 \pm 0.91$ & $6.42 \pm 1.01$ & 0.98 \\
GDS $^{\mathrm{f}}$ & $10.66 \pm 6.53$ & $10.10 \pm 6.12$ & 0.79 \\
Global DS $^{\mathrm{g}}$ & $2.86 \pm 0.74$ & $3.0 \pm 0.47$ & 0.50 \\
IADL $^{\text {h }}$ & $6.2 \pm 1.56$ & $6.1 \pm 1.44$ & 0.68 \\
\hline
\end{tabular}

${ }^{a}$ Values are expressed as means \pm SD. ${ }^{b}$ ADAS-cog, Alzheimer's Disease Assessment Scale-cognitive subscale; ${ }^{\mathrm{C}} \mathrm{MMSE}$, Mini Mental State Examination; ${ }^{d}$ ADAS-Non-Cog, Alzheimer's Disease Assessment Scale-Non-Cognitive Section; ePSMS, Physical Self-Maintenance Scale; ${ }^{f}$ GDS, Geriatric Depression Scale; Global, ${ }^{9}$ Global Deterioration Scale (DS) for Assessment of Primary Degenerative Dementia; ${ }^{\text {h } I A D L, ~ I n s t r u m e n t a l ~ A c t i v i t i e s ~ o f ~ D a i l y ~ L i v i n g ~ S c a l e . ~}$

decrease of cholesterol levels was observed in the IFN $\beta 1$ a group but not in the placebo arm (3/19 versus $0 / 15$, $P=<0.05)$.

\section{Efficacy}

Patients in the placebo and study drug randomized groups shared the same baseline characteristics with no significant differences, as shown in Table 2. Similarly, the baseline means scores of all parameters measured in the study did not differ in the two arms, confirming that the randomization did not generate any bias in the protocol, as detailed in Table 3.
The primary outcome measure, ADAS-Cog, showed no significant progression of AD during the 28-week treatment period, while a worsening was observed during follow-up, as shown by the delta values of ADASCog score when comparing the different time points of the trial (Table 4). However, no significant differences of overall efficacy were observed between placebo and treatment group.

The same trend was observed for MMSE, and ADASNonCog scores, thus indicating a positive effect of treatment on the disease decline but without significant differences between the two treatments arms (Table 4).

Interestingly, there was a significant improvement of both PSMS and IADL scores in the IFN $\beta 1$ a group at follow-up compared with both baseline and end of treatment. The Global Deterioration Scale showed a modest decline in patients of the two arms during the treatment period and between baseline and follow-up. However, no significant differences were observed. Similarly, CIBICplus, measured at 28 and 52 weeks, did not show any differences between arms (data not shown). Conversely, the GDS score significantly improved in the placebo group, overall and during follow up (Table 4).

\section{Discussion}

New treatments for MS are expected to become available within the next 2 years [22]. Conversely, AD is still lacking a convincing strategy to halt the progressive decline of cognitive function associated with protein accumulation within the brain. The now well-established

Table 4 Analysis of change (delta values) of outcomes at study time points ${ }^{a}$

\begin{tabular}{|c|c|c|c|c|}
\hline Test & Treatment & Delta value $T 1^{b}$ versus $T 2^{c}$ & Delta value $T 2$ versus $T 3^{d}$ & Delta value T1 versus T3 \\
\hline \multirow[t]{2}{*}{ ADAS-Cog $^{e}$} & IFN $\beta$ 1a & $0.144 \pm 1.16$ & $-2.17 \pm 1.01(p=0.031)$ & $-2.02 \pm 1.58$ \\
\hline & Placebo & $2.25 \pm 1.05$ & $-2.78 \pm .1 .02$ & $-0.52 \pm 1.86$ \\
\hline \multirow[t]{2}{*}{ MMSE $^{f}$} & IFN $\beta$ 1a & $0.78 \pm 0.52$ & $-1.81 \pm 0.69(p=0.037)$ & $-1.02 \pm 1.03$ \\
\hline & Placebo & $0.73 \pm 0.98$ & $-1.68 \pm 0.76$ & $-0.95 \pm 1.0$ \\
\hline \multirow[t]{2}{*}{ ADAS-NonCog 9} & IFN $\beta$ 1a & $-0.26 \pm 0.53$ & $-0.84 \pm 0.35$ & $-1.10 \pm 0.65$ \\
\hline & Placebo & $0.86 \pm 0.75$ & $-2.0 \pm 1.099$ & $-1.13 \pm 1.26$ \\
\hline \multirow[t]{2}{*}{ PSMS $^{h}$} & IFN $\beta$ 1a & $0.31 \pm 0.23$ & $1.05 \pm 0.66(p=0.0459)$ & $1.36 \pm 0.76(p=0.025)$ \\
\hline & Placebo & $0.6 \pm 0.6$ & $-0.13 \pm 0.29$ & $0.46 \pm 0.33$ \\
\hline \multirow[t]{2}{*}{ GDS $^{\mathrm{i}}$} & IFN $\beta$ 1a & $0.42 \pm 0.94$ & $-1.10 \pm 0.79$ & $-0.68 \pm 1.35$ \\
\hline & Placebo & $2.0 \pm 1.34$ & $1.57 \pm 0.83(p=0.0418)$ & $3.57 \pm 1.24(p=0.009)$ \\
\hline \multirow[t]{2}{*}{ Global DS } & IFNß 1a & $-0.05 \pm 0.17$ & $-0.21 \pm 0.12$ & $-0.26 \pm 0.18$ \\
\hline & Placebo & $-0.13 \pm 0.13$ & $-0.2 \pm 0.10$ & $-0.33 \pm 0.15$ \\
\hline \multirow[t]{2}{*}{$\mathrm{IADL}^{\mathrm{k}}$} & IFN $\beta$ 1a & $0.26 \pm 0.34$ & $\mathbf{0 . 9 4} \pm \mathbf{0 . 3 7}(p=0.0306)$ & $1.20 \pm 0.59(p=0.041)$ \\
\hline & Placebo & $0.6 \pm 0.36$ & $-0.06 \pm 0.18$ & $0.53 \pm 0.36$ \\
\hline
\end{tabular}

${ }^{a}$ Values are shown as means \pm SEM; Negative change indicates worsening of condition. In brackets are reported $p$ values (by arm) when statistically significant. ${ }^{\mathrm{b}} \mathrm{T} 1$ = baseline (week 0); ${ }^{\mathrm{C}} \mathrm{T} 2$ = end of treatment (week 28); ${ }^{\mathrm{d}} \mathrm{T} 3$ = follow-up (week 54). ${ }^{\mathrm{e}} \mathrm{ADAS}$-cog, Alzheimer's Disease Assessment Scale-cognitive subscale; ${ }^{\mathrm{f}} \mathrm{MMSE}$,

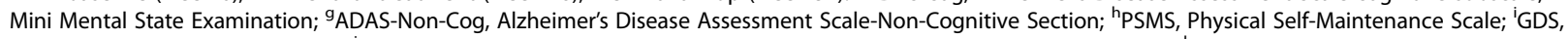
Geriatric Depression Scale; Global, 'jGlobal Deterioration Scale (DS) for Assessment of Primary Degenerative Dementia; ${ }^{k}$ IADL, Instrumental Activities of Daily Living Scale. 
contribution of inflammatory mechanisms to the pathogenesis of plaque formation offers an interesting target for treatment. At present, numerous attempts to alter the inflammatory processes in $\mathrm{AD}$ have been performed using different anti-inflammatory drugs [20,21].

Although IFN $\beta 1$ a has a well-established positive safety profile in the young adult (the typical MS population), little is known in older patients (typical AD population). We assessed the safety of IFN $\beta 1$ a for the treatment of patients affected by mild $A D$ and found that this drug was well tolerated. The number of adverse events reported was low and their severity was mild to moderate and comparable between the two arms of the study.

Our study was clearly not powered to demonstrate efficacy. However, although no statistically significant difference between the IFN $\beta 1 \mathrm{a}$ and the placebo groups was reported for the major outcome measure of the study, the ADAS-Cog score, the improvement noted in the IFN $\beta 1$ a treatment group was maintained during the 24-week follow-up period. Similarly, improvement in the ADAS-NonCog score was maintained. Importantly, significant improvements in the IADL and in the PSMS scores, extending to the follow-up phase, were observed in the IFN $\beta 1$ a treatment group.

These results show that, although treatment with IFN 31 a did not perform better than placebo during the treatment period, a slower decline could be observed in the active drug group during the follow-up period, indicating a prolonged protective effect of IFN $\beta 1$.

Paradoxically, but not surprisingly, we found that the placebo had an antidepressant effect, as shown by the significant improvement in the Geriatric Depression Scale, suggesting that this effect may have been responsible for improvement in the placebo group during the 6 months of treatment. Mood elevation engendered by the placebo may have counterbalanced any positive cognitive outcome of the active drug, which is well known to produce a transient mood decline during the first months of treatment [23].

Interestingly, a cholesterol lowering trend was observed in IFN $\beta 1$ a treated patients, indicating a possible additional mechanism for its efficacy since cholesterol might play a role in the pathogenesis of $\mathrm{AD}$, and cholesterol lowering agents, such as statins, have been tested as treatment for AD [24,25]. Recently, Weinstock-Gutmann et al. [26], reported that in early MS patients, higher levels of low density lipoprotein cholesterol (LDL-C) and total cholesterol (TC) are associated with increased inflammation (by MRI evaluation) in subjects affected by a clinically isolated syndrome and treated with intramuscular injection of IFN $\beta 1$.

In conclusion, our study demonstrates the tolerability, short-term safety and feasibility of using IFN $\beta 1$ a in treatment of older patients at risk for AD-related cognitive decline. Our findings suggest that the strategy used here should be further investigated in larger studies targeting subjects in early stage disease where inflammatorymediated facilitation of misfolded-protein accumulation is more likely to occur.

\section{Abbreviations \\ ADAS-cog: Alzheimer's Disease Assessment Scale-cognitive subscale; ADAS-Non-Cog: Alzheimer's Disease Assessment Scale-Non-Cognitive Section; ALT: alanine aminotransferase; AST: aspartate aminotransferase; BBB: blood-brain barrier; GDS: Geriatric Depression Scale; Global: Global Deterioration Scale for Assessment of Primary Degenerative Dementia; IADL: Instrumental Activities of Daily Living Scale; ICAM-1: intercellular adhesion molecules; IFNß1a: interferon beta 1a; LDL-C: Iow density lipoprotein cholesterol; MHC: major histocompatibility complex; MMSE: Mini Mental State Examination; PSMS: Physical Self-Maintenance Scale; $\mathrm{TSH}$ : thyroid stimulating hormone.}

\section{Competing interests}

The authors declare that they have no competing interests.

\section{Authors' contributions}

LMEG generated the idea at the base of the study, searched for economical support, organized and carried out the study at its Center, wrote and edited the final version of the manuscript; GZ enrolled the majority of subjects and drafted the first version of the manuscript, FI, AEC, GB and SR organized and carried out the study at their Centers, collected and revised the clinical data and contributed to the preparation of the manuscript; AP contributed to the overall development and organization of the study, collected and analyzed the data and drafted and corrected the manuscript. All authors read and approved the final manuscript.

\section{Acknowledgements}

The statistical analysis plan (SAP) was performed by a certified statistician of the CRO that performed the monitoring, Opera Srl-Via Sampierdarena 33/2 16149 Genova, Italy. Study funding: the study was supported by Merck Serono-Italy An affiliate of Merck KGA, Darmsdadt, Germany.

The authors wish to thank Sabina Cilia, William Di Noto, Adele Gallo and Fabio Ruvolo for their invaluable professional counseling and support when the REAL project was launched at the AUSL2 of Caltanissetta (Italy).

\section{Author details}

"U.O. di Neurologia, Fondazione Istituto San Raffaele "G. Giglio" di Cefalù, Contrada Pietrapollastra, 90015 Cefalù, PA, Italy. ${ }^{2}$ U.V.A. Neurologia, Azienda Ospedaliera Garibaldi-Nesima, Via Palermo 135, 95122 Catania, Italy. ${ }^{3}$ U.O.C. Provinciale di Neurologia, Via Papa Giovanni XIII, 97019 Vittoria, RG, Italy. ${ }^{4}$ Clinica Neurologica, IRCCS Neuromed, Via Atinense, 18, 86077 Pozzilli, IS, Italy. ${ }^{5}$ Centro U.V.A., Dipartimento di Scienze Neurologiche, Università degli Studi di Roma "La Sapienza", Viale dell'Università, 30, 00185 Roma, Italy. ${ }^{6}$ MerckSerono S.A., Merck Serono-Italy An affiliate of Merck KGA, Darmsdadt, Germany, Via Casilina 125, 00176 Roma, Italy.

Received: 11 November 2013 Accepted: 26 January 2014

Published: 13 February 2014

\section{References}

1. Bishop NA, LU T, Yankner BA: Neural mechanisms of ageing and cognitive decline. Nature 2010, 464:529-535.

2. Hebert LE, Scherr PA, Bienias JL, Bennett DA, Evans DA: Alzheimer disease in the US population: prevalence estimates using the 2000 census. Arch Neurol 2003, 60:1119-1122.

3. De Strooper B: Proteases and proteolysis in Alzheimer disease: a multifactorial view on the disease process. Physiol Rev 2010, 90:465-494.

4. Kalaria RN: Microglia and Alzheimer's disease. Curr Opin Hematol 1999, 6:15-24.

5. McGeer PL, McGeer EG: The inflammatory response system of brain: implications for therapy of Alzheimer and other neurodegenerative diseases. Brain Res Brain Res Rev 1995, 21:195-218.

6. Griffin WS, Stanley LC, Ling C, White L, MacLeod V, Perrot L, White CL III, Araoz C: Brain interleukin 1 and S-100 immunoreactivity are elevated in 
down syndrome and Alzheimer disease. Proc Natl Acad Sci U S A 1989, 86:7611-7615

7. Kalaria RN: The blood-brain barrier and cerebrovascular pathology in Alzheimer's disease. Ann N Y Acad Sci 1999, 893:113-125.

8. Ferguson B, Matyszak MK, Esiri MM, Perry VH: Axonal damage in acute multiple sclerosis lesions. Brain 1997, 120(Pt 3):393-399.

9. Huang YM, Xiao BG, Ozenci V, Kouwenhoven M, Teleshova N, Fredrikson S, Link H: Multiple sclerosis is associated with high levels of circulating dendritic cells secreting pro-inflammatory cytokines. J Neuroimmunol 1999, 99:82-90.

10. Trapp BD, Nave KA: Multiple sclerosis: an immune or neurodegenerative disorder? Annu Rev Neurosci 2008, 31:247-269.

11. Weissert $R$, Svenningsson $A$, Lobell $A$, de Graaf $K L$, Andersson $R$, Olsson $T$ : Molecular and genetic requirements for preferential recruitment of TCRBV8S2+ T cells in Lewis rat experimental autoimmune encephalomyelitis. J Immunol 1998, 160:681-690.

12. Manfredonia F, Pasquali L, Dardano A, ludice A, Murri L, Monzani F: Review of the clinical evidence for interferon beta 1a (Rebif) in the treatment of multiple sclerosis. Neuropsychiatr Dis Treat 2008, 4:321-336

13. Rothuizen LE, Buclin T, Spertini F, Trinchard I, Munafo A, Buchwalder PA, Ythier A, Biollaz J: Influence of interferon beta-1a dose frequency on PBMC cytokine secretion and biological effect markers. J Neuroimmunol 1999, 99:131-141.

14. Yong WW, Chabot S, Stuve O, Williams G: Interferon beta in the treatment of multiple sclerosis: mechanisms of action. Neurology 1998, 51:682-689.

15. Dhib-Jalbut S: Mechanisms of action of interferons and glatiramer acetate in multiple sclerosis. Neurology 2002, 58(Suppl 4):S3-S9.

16. Galboiz Y, Shapiro S, Lahat N, Rawashdeh H, Miller A: Matrix metalloproteinases and their tissue inhibitors as markers of disease subtype and response to interferon-beta therapy in relapsing and secondary-progressive multiple sclerosis patients. Ann Neurol 2001, 50:443-451.

17. Biernacki K, Antel JP, Blain M, Narayanan S, Arnold DL, Prat A: Interferon beta promotes nerve growth factor secretion early in the course of multiple sclerosis. Arch Neurol 2005, 62:563-568.

18. Sattler MB, Demmer I, Williams SK, Maier K, Merkler D, Gadjanski I, Stadelmann C, Bahr M, Diem R: Effects of interferon-beta-1a on neuronal survival under autoimmune inflammatory conditions. Exp Neurol 2006, 201:172-181.

19. Patti F, Amato MP, Bastianello S, Caniatti L, Di Monte E, Ferrazza P, Goretti B, Gallo P, Morra VB, Lo Fermo S, Picconi O, Tola MR, Trojano M, COGIMUS Study Group: Effects of immunomodulatory treatment with subcutaneous interferon beta-1a on cognitive decline in mildly disabled patients with relapsing-remitting multiple sclerosis. Mult Scler 2010, 16:68-77.

20. Fernández PL, Britton GB, Rao KS: Potential immunotargets for Alzheimer's disease treatment strategies. J Alzheimers Dis 2013, 33:297-312.

21. Hensley K: Neuroinflammation in Alzheimer's disease: mechanisms, pathologic consequences, and potential for therapeutic manipulation. J Alzheimers Dis 2010, 21:1-14.

22. Tullman MJ: A review of current and emerging therapeutic strategies in multiple sclerosis. Am J Manag Care 2013, 19(Suppl):s21-s27.

23. Patten SB, Francis G, Metz LM, Lopez-Bresnahan M, Chang P, Curtin F: The relationship between depression and interferon beta-1a therapy in patients with multiple sclerosis. Mult Scler 2005, 11:175-181.

24. Candore G, Bulati M, Caruso C, Castiglia L, Colonna-Romano G, Di Bona D, Duro G, Lio D, Matranga D, Pellicano M, Rizzo C, Scapagnini G, Vasto S: Inflammation, cytokines, immune response, apolipoprotein $\mathrm{E}$, cholesterol, and oxidative stress in Alzheimer disease: therapeutic implications. Rejuvenation Res 2010, 13:301-313.

25. Ullrich C, Pirchl M, Humpel C: Hypercholesterolemia in rats impairs the cholinergic system and leads to memory deficits. Mol Cell Neurosci 2010 45:408-417.
26. Weinstock-Guttman B, Zivadinov R, Horakova D, Havrdova E, Qu J, Shyh G, Lakota E, O'Connor K, Badgett D, Tamaño-Blanco M, Tyblova M, Hussein S, Bergsland N, Willis L, Krasensky J, Vaneckova M, Seidl Z, Ramanathan M: Lipid profiles are associated with lesion formation over 24 months in interferon- $\beta$ treated patients following the first demyelinating event. J Neurol Neurosurg Psychiatry 2013, 84:1186-1191.

doi:10.1186/1742-2094-11-30

Cite this article as: Grimaldi et al:: A pilot study on the use of interferon beta-1a in early Alzheimer's disease subjects. Journal of Neuroinflammation 2014 11:30.

\section{Submit your next manuscript to BioMed Central and take full advantage of:}

- Convenient online submission

- Thorough peer review

- No space constraints or color figure charges

- Immediate publication on acceptance

- Inclusion in PubMed, CAS, Scopus and Google Scholar

- Research which is freely available for redistribution

Submit your manuscript at www.biomedcentral.com/submit
C) Biomed Central 